\title{
Knowledgeshare
}

\section{Equality and Human Rights Commission - Is Britain Fairer?}

\section{Nicky Hudson}

Is Britain Fairer?, the Equality and Human Rights Commission's statutory five-yearly report on equality and human rights progress in England, Scotland and Wales, was published on Friday 30 October 2015. It is the most comprehensive review ever carried out on progress towards greater equality and human rights protection in Britain, revealing that, while life has become fairer over the past five years for many people, for others, progress has stalled and for some- in particular young people and poor White boys - life on many fronts has got worse.

Is Britain Fairer? draws on a wide range of major datasets and the Commission's own analysis to reveal how, as the country becomes more ethnically and religiously diverse than at any point in its history, new complexities mean many existing assumptions about which of us encounter greater challenges may no longer hold true.

Analysis in the review identifies eight key challenges for policy makers, statutory bodies and other groups to address over the coming years:

1. Improve the evidence and the ability to assess how fair society is.

2. Raise standards and close attainment gaps in education.

3. Encourage fair recruitment, development and reward in employment.

4. Support improved living conditions in cohesive communities.

5. Encourage democratic participation and ensure access to justice.

6. Improve access to mental health services and support for those experiencing (or at risk of experiencing) poor mental health

7. Prevent abuse, neglect and ill-treatment in care and detention.

8. Tackle targeted harassment and abuse of people who share particular protected characteristics.

The following are available alongside the full report: Is Britain Fairer? The State of Equality and Human Rights 2015, London, Equality and Human Rights Commission http://www. equalityhumanrights.com

A standalone executive summary is available in English, Welsh, BSL and Easy Read versions.

Join the discussion:

The Commission invites you to join the debate by tweeting or retweeting using the hashtag \#IsBritainFairer, by liking or sharing EHRC's posts on Facebook and LinkedIn, or by blogging about Is Britain Fairer? with links to www.equalityhumanrights. com/IsBritainFairer.
From: http://www.edf.org.uk/blog/equality-and-human-rightscommission-is-britain-fairer/

\section{Government announcement of new measures to eradicate gender pay inequality in the UK}

On 25 October 2015, the Prime Minister announced measures to remove barriers to success in the workplace including: requiring large employers to publish information about their bonuses for men and women, extending the plan for gender pay gap reporting to the public sector, and working with business to eliminate all-male boards in the FTSE 350.

The announcement is part of a wider plan to help women and black and ethnic minority groups as part of the Government's determination to extend opportunity to all.

From: http://www.edf.org.uk/blog/government-announcementof-new-measures-to-eradicate-gender-pay-inequality/

\section{'Race', racism and participation in sport Better Health Briefing Paper 40.}

Race Equality Foundation. Kevin Hylton; Jonathan Long; Daniel Parnell; A.J. Rankin.

This briefing outlines three propositions in what is an increasingly complex field of theory, policy and practice:

1. 'Race' and ethnicity influence the way sport is accessed and experienced;

2. Responses to racial disparities and discrimination require coherent and specific approaches at multiple levels (individual, organisational, structural);

3. Race equality policies require clear thought but implementation needs thoughtful action.

This paper considers "sport" in both a formal context of active participation, and participation in physical activity more generally, considering possible preferences for informal or community contexts for some black and minority ethnic groups. It also explores the role that formal structures and bodies can play in increasing participation amongst these individuals.

\section{Key messages}

- Racism and racialised inequalities significantly influence black and minority ethnic communities' access, participation and experiences of sport.

- Black and minority ethnic community experiences of racism differ within and across ethnic groups. Intersections between gender, class, age and disability also influence experiences and participation in sport.

- In light of the existence of racism in sport, it is unsurprising that many black and minority ethnic groups favour physical activity (PA) and health programmes that can be pursued away from the mainstream. 
- Race equality in sport requires a critical approach that understands the nuances of tackling different experiences of racism in policy and practice. One size does not fit all.

See: http://www.better-health.org.uk/briefings/race-racismand-participation-sport

Pregnancy and maternity-related discrimination and disadvantage. First findings: surveys of employers and mothers (BIS Research Paper no. 235)

Pregnancy discrimination and disadvantage in the workplace The Department for Business, Innovation and Skills (BIS) and the EHRC jointly commissioned IFF Research in 2014 to investigate the prevalence and nature of pregnancy discrimination and disadvantage in the workshop. This was the first comprehensive analysis of these issues since the Equal Opportunities Commission conducted a formal investigation into discrimination against new and expectant mothers in the workplace in 2003-05.

Through interviews with 3,034 employers and 3,254 mothers, IFF explored the views and experiences of employers and mothers on a range of issues related to managing pregnancy, maternity leave and mothers returning to work.

\section{Key findings included that:}

- The majority of employers reported that it was in their interests to support pregnant women and those on maternity leave and they agreed that statutory rights relating to pregnancy and maternity are reasonable and easy to implement.

- Around one in nine mothers (11 per cent) reported that they were either dismissed; made compulsorily redundant, where others in the workplace were not; or treated so poorly that they had to leave their job. If scaled up to the general population, this could mean as many as 54,000 mothers a year were so affected.

- One in five mothers said that they had experienced harassment or negative comments related to pregnancy or flexible working from their employer and/or colleagues. If scaled up to the general population, this could mean as many as 100,000 mothers a year were so affected.

- Ten per cent of mothers said that their employer discouraged them from attending antenatal appointments. If scaled up to the general population, this could mean as many as 53,000 mothers a year were so affected.

Pregnancy and maternity-related discrimination and disadvantage. First findings: surveys of employers and mothers (BIS Research Paper no. 235) is available at:

See: http://www.equalityhumanrights.com/about-us/ our-work/key-projects/managing-pregnancy-and-maternityworkplace/report

A final report of pregnancy discrimination and disadvantage in the workplace is due to be published by the end of 2015 and will be covered in a future database newsletter.

\section{Equality and Human Rights Commission Reading Lists}

As a regulator, the Commission bases its decisions and policies on a robust evidence base. The Commission's Library has drafted a selection of equality themed reading lists to support business projects and priorities. These lists cover the equality, human rights and good relations mandates, and the seven equality strands and are published for wider consumption:

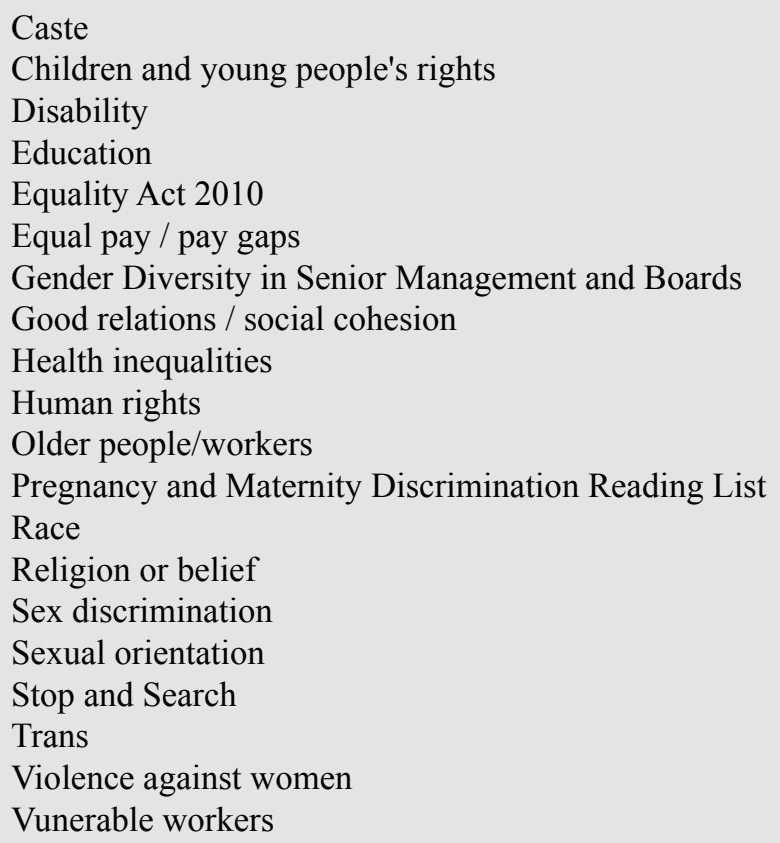

